\title{
Testing the Spatial Voting Theories on a Computational Model: A Demonstration of the Polarizing Influence of Directional Voting
}

\author{
Hurol Aslan \\ Department of Computer Technology and Information Systems, \\ Erdemli Applied School of Technology and Management, Mersin University \\ Erdemli, Mersin, Turkey \\ E-mail: hurol_aslan@mersin.edu.tr
}

\begin{abstract}
This study proposes a Gaussian utility function for the proximity theory so that it only describes the variation of party affinity of the voter with the ideological distance from the party. Eliminating the repulsive portion of its currently adopted utility function distinguishes the proximity theory from the directional theory. Instead of trying to fit actual voting behavior to either utility function, the functions are tested on an idealized computer model of the voters' opinion space to test their suitability. By testing varying linear combination of the utility functions of the two theories, optimum locations of parties are found that will maximize the average value of the combined voter utility function. Results indicate that catch-all parties with large voter bases choose locations near the neutral center, but increasing the contribution from the directional utility function pushes the parties further away from the neutral center. These findings support the observed relationship between ideological polarization and the directional voting tendency. The conclusion is that a linear combination of the two utility functions appear to be more suitable to explain idealized voter behavior.
\end{abstract}

Keywords: spatial voting, proximity theory, directional theory, computational model, optimization

DOI: $10.7176 / \mathrm{JSTR} / 6-02-04$

\section{Introduction}

A spatial voting model is set up on an imaginary opinion space whose dimensions represent the range of opinions between two extremes on distinct political viewpoints. Each voter or candidate is assigned a location in that space which represents the set of opinions they hold as a combination of coordinates along those dimensions. As Rabinowitz and Macdonald (1989) summarize, early popular spatial models indicated that a voter would evaluate candidates according to their respective locations in the opinion space and choose the closest candidate in terms of the distance between the voter's and the candidate's locations. Because of the way "perceived proximity affects party or candidate preferences" (Dinas, Hartman, \& van Spanje, 2016), the basis of such a model is called the "proximity theory."

It should be noted that, the average voter's ability to perceive the proximity of a candidate/party that casts doubt on the validity of the proximity theory. McDonald et. al. (1995) point at the "higher cognitive demands" of the proximity theory and argue that empirical results favor an alternative theory where the average voter chooses the candidates who have taken the same sides as him/her on most issues. Voting on issues is the basis for the "directional theory" proposed by two of these authors (Rabinowitz \& Macdonald , 1989). According to the directional theory, views on issues are not just additional proximity measures; voters care how strongly and in which directions parties or candidates have reacted to the current issues.

This point of view is not without supporters; Boatright (2008), for example, notes that the proximity theory is useful when voters are well-informed people like some committee members, but many voters do not make ideologically informed choices. Joesten and Stone (2014) also acknowledge that voters lacking sufficient sophistication "may not measure up to the cognitive demands of spatial voting models," and try to bring arguments explaining how voters can make spatially meaningful choices without complete information on candidates' positions. A recent study has employed an online voting simulation 
to demonstrate the decision processes of knowledgeable voters and shown they vote in accordance with the proximity theory (Shane \& Roy, 2014). In summary, the theoretical basis of the proximity model looks sound, though voters' uncertainty may distort the evidence. It is also suggested that the partisan bias is mistaken for directional voting behavior (Tomz, Houweling, \& Sniderman, 2006).

\subsection{The Academic Debate on the Competing Models}

Before presenting the model to compare the mathematical expressions of the proximity and directional voting theories, it may be of use to present some glimpses of how the recent academic debate on the merits of those models have progressed.

The founders of the directional theory utilized the data from four consecutive U.S. elections from 1972 to 1984 and asked how the voters positioned themselves and the candidates of those elections on sevenpoint issue scales (Rabinowitz \& Macdonald , 1989). They concluded that the directional theory explained more of the variance and overall results favored their model. Their additional evidence came from the preference towards the candidates who dared to take stronger stances on contended issues rather than safely remaining in the neutral zone, as the proximity theory predicted. In a later study (McDonald, Rabinowitz, \& Listhaug, 1995), the authors made use of data from Norway and they concluded the directional theory also explained the way voters evaluated the candidates in a multi-party system.

The evidence presented in favor of directional voting was not readily accepted by some other researchers. Westholm (1997), for example, questioned the unclearly defined "region of acceptability" principle (McDonald, Listhaug, \& Rabinowitz, 1991) of the directional theory, which was not found in the proximity theory. The author also criticized the "ad hoc shifts" from one mathematical expression for voter utility to another. Finally, the author noted that the high correlation between the predictions of two competing theories gave false credence to the directional theory over the proximity theory.

In a prompt reply to these criticisms (McDonald, Rabinowitz, \& Listhaug, 1998), defenders of the directional model admitted that the scalar product used in the directional model is very similar to the voter-candidate distance calculated in the proximity model, making the comparison of the two theories difficult. However, they did not fail to find flaws in Westholm's (1997) attempt to rescue the proximity theory. They argued that the eccentricity parameter introduced by Westholm to rehabilitate the proximity theory was essentially indistinguishable from the scalar product that formed the basis of the directional theory. The concluded their defense by re-emphasizing "the importance of taking strong stands on issues to generate support."

Political success derived from taking stronger (and even somewhat extreme) stances have been noted by other researchers (Leimgruber, Hangartner, \& Leeman, 2010). In a two-dimensional space made up of the axes representing economic and cultural dimensions, the authors concluded that the unexpected preference given by some sophisticated Swiss voters to extreme views contradicted the proximity theory, but could be explained by the directional theory. Kedar (2005) is another author who acknowledged that voters could prefer parties with more extreme views, possibly hoping that those parties will influence the public policies in certain directions.

The few conflicting studies mentioned above have made use of data from voter surveys and election results. It has been argued that the data and the methods they used might just not provide sufficiently strong evidence to place one theory above the other (Lewis \& King, 1999). While taking a seemingly neutral stance between the two competing theories, Lewis and King questioned the wisdom of relying on random voters' responses to "imprecisely worded survey questions" and noted that defenders of both theories could make untested assumptions to arrive at conclusions justifying themselves. They concluded that a final judgment would require better measurement devices and experimental methodologies.

Naturally, the best experiments available to political scientists are elections, which do provide a substantial amount of useful data at regular intervals. In a comparative study of 27 multi-party systems across Europe, Fazekas and Méder (2013) evaluated the predictive and explanatory abilities of the two theories and concluded that the data lent more empirical support to the proximity theory, but also noted that this support was substantially reduced in polarized political systems. The relationship between political polarization and directional voting tendency was also the main focus of the paper by PardosPrado and Dinas (2010). In that paper, the authors noted that the proximity theory was dominant in less polarized systems, where the centripetal tendencies pulled both voters and parties closer to the neutral center. However, in countries like Italy and Hungary, where the political competition was strongly influenced by centrifugal tendencies, the directional theory was more applicable to voters' choices. Lachat (2008) established the role of the party system polarization on directional voting through a voters' survey conducted over European countries with multi-party systems. He noted that, in polarized systems, parties would refer to their ideologies more frequently and thus issues of ideology would become emotionally more significant for the voters.

$30 \mid \mathrm{P}$ a g e 


\section{Method}

\subsection{The Proposed Model of the Opinion Space}

This paper utilizes uniformly circular, two-dimensional model of the opinion space where each point represents one voter with a specific pair of opinions represented by the coordinates of that point. The model was introduced in a previous work to show that, political parties trying to please their own constituents would settle at optimum locations that would maximize the average voter utility function value across the opinion space. The results of that study indicated that these optimum locations were unique and dependent on the parties' voter base widths. While catch-all parties appealing to larger masses took positions near the neutral center, parties with smaller voter bases were pushed to fringe positions. These results were consistent with the observed divergent positioning tendencies of parties competing in proportional representation systems, where smaller contenders could still partake in winning coalitions (Dow, 2001).

Since the generally-accepted spatial model based on Downs' median-voter theory predicted that parties would converge at the neutral center to maximize their votes, there have been attempts to modify it such conflicting observations (Schofield, 2007). However, the principle of voter utility maximization not only makes such modifications unnecessary, but it also helped find equilibrium points in a way simpler than utilizing the game theory (Chisik \& Emke, 2006).

\subsection{Voter Utility Functions for the Spatial Voting Theories}

The first step in these demonstrations is defining the voter utility functions for the competing spatial voting theories. By referring to prior sources, Lacy and Paolino (2010) notes that the voter utility function for the proximity theory is either a decreasing linear function or a decreasing quadratic function centered at the party's position. However, such vertically unbounded functions decrease continuously with the perceived distance between the voter and the party, as if the increasing distance creates a repulsion towards a party, just like the directional voting theory suggests. To make the two theories more distinguishable in terms of the utility function, we have opted for a bounded function, namely, the normal density function proposed by Davis, Hinich an Ordeshook (1970). Their choice of this utility function was criticized for not having an "empirical justification" (Serra, 2018), but the absence of justification may only be due to the lack of studies and models utilizing it.

By introducing the full-width-at-half-maximum (FWHM) parameter $w$, as a measure of a political party's degree of popularity or the voter base size, the following Gaussian function can give a party's utility value that a voter located at $(x, y)$ will attribute to a party located at $\left(x_{i}, y_{i}\right)$ in accordance with the proximity voting theory:

$$
F_{i_{\text {prox }}}(x, y)=\exp \left(-4 \ln (2)\left[\left(x-x_{i}\right)^{2}-\left(y-y_{i}\right)^{2}\right] / w_{i}^{2}\right)
$$

The following figure shows the three-dimensional shaded model of this utility function of a major party with $\mathrm{FWHM}_{1}=1.0$ located at $\left(x_{1}=+0.25, y_{1}=-0.25\right)$ over the uniformly circular opinion space:

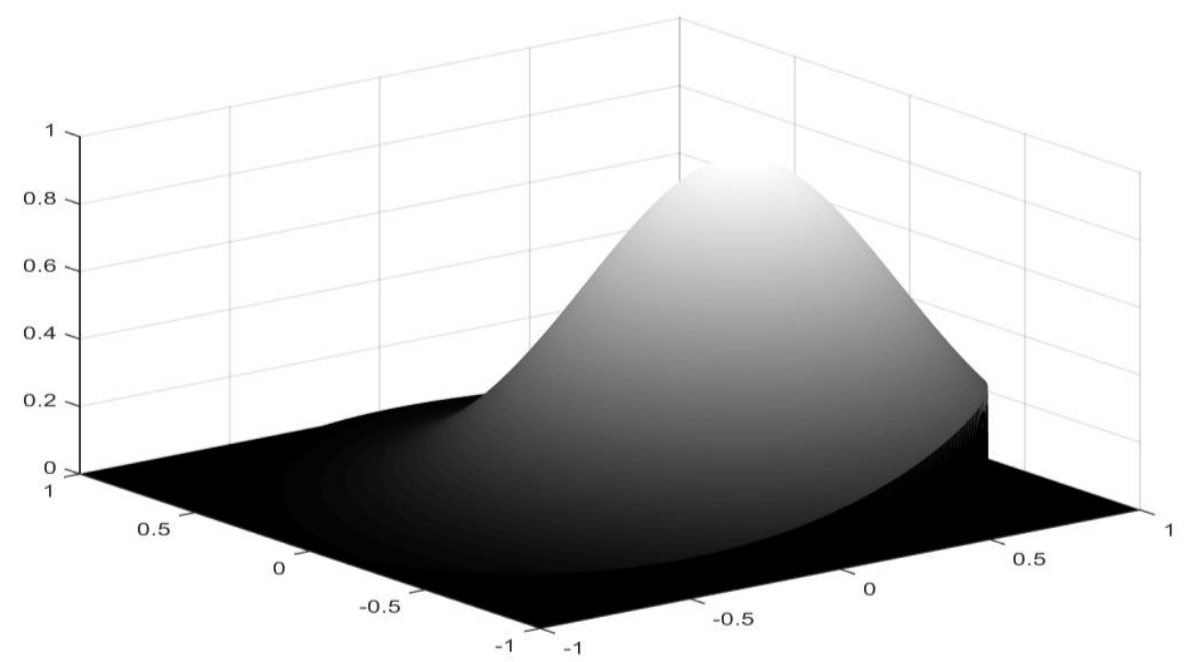

Figure 1. Three-dimensional model of the voter utility function for a major party with $F W H M_{1}=1.0$ located at $\quad\left(x_{1}=0.25, y_{1}=-0.25\right)$ according to the proximity theory.

31 | P a g e 
The voter utility function according to the directional theory is actually the scalar product of the opinion vectors of the voter and the contender (Rabinowitz \& Macdonald , 1989). Using the parameters used in the above equation, the utility function for the directional voting theory will be in the following form:

$F_{i_{\text {direct }}}(x, y)=\left(x x_{i}\right)+\left(y y_{i}\right)$

In a model of an electoral competition where the voters evaluate the closer parties by proximity, but distant parties directionally, the voter utility functions of the two theories can be combined linearly:

$F_{i}(x, y)=\exp \left(-\frac{4 \ln (2)\left[\left(x-x_{i}\right)^{2}-\left(y-y_{i}\right)^{2}\right]}{w_{i}{ }^{2}}\right)+r_{d}\left[\left(x x_{i}\right)+\left(y y_{i}\right)\right]$

The following figure shows how the voter utility function depicted above would look over the uniformly circular opinion space, with the directional voting utility function contributing with a linear factor of $r_{d}$ $=0.5$ :

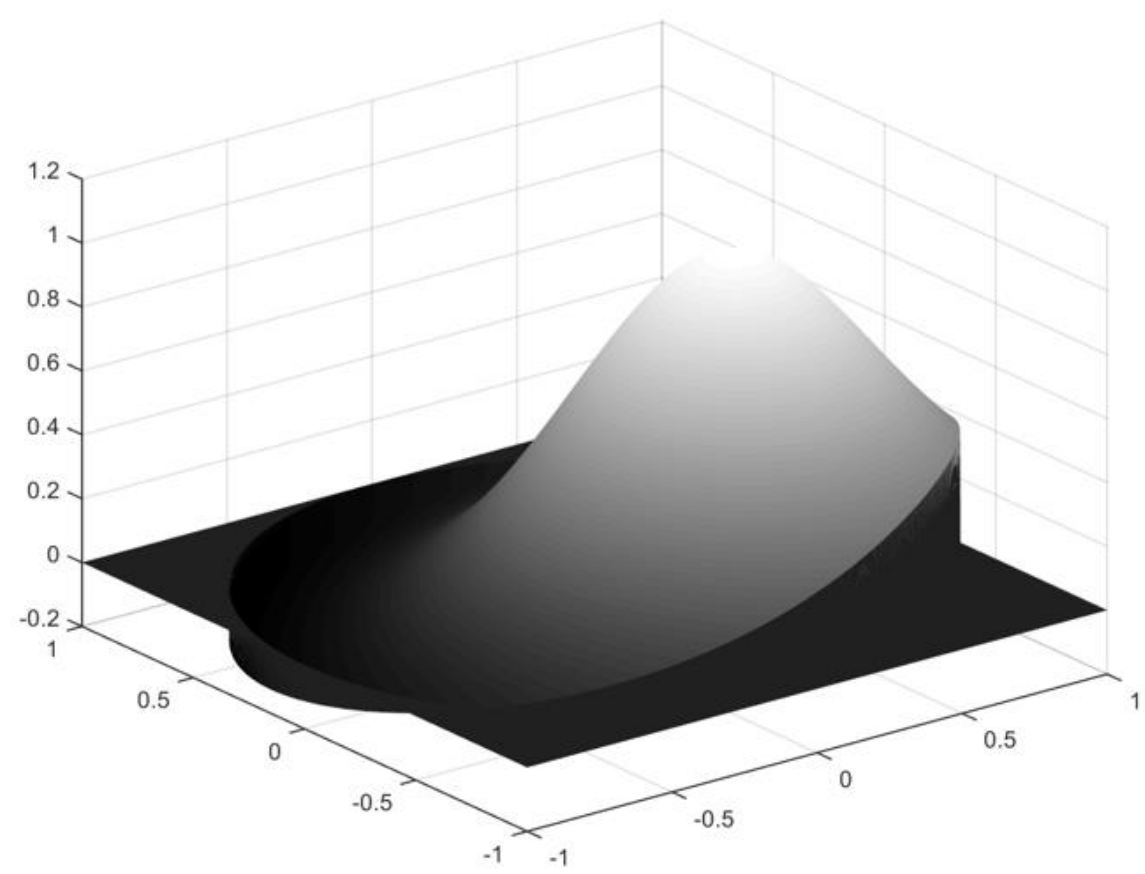

Figure 2. Three-dimensional model of the voter utility function for a major party with $F W H M_{1}=1.0$ located at $\left(x_{1}=0.25, y_{1}=-0.25\right)$ with a directional voting contribution ratio $r_{d}=0.5$.

\subsection{Application of the Model}

The proposed model was used to find optimum locations for two or three parties competing over an idealized model of a perfectly proportional representation voting system. The optimum locations were those which would maximize the average voter utility function across this model space, the utility function being a linear combination of Gaussian proximity voting function and the directional voting function described above.

The model was uniformly circular, representing a virtual population of voters each of which was at different coordinates representing a specific set of opinions along two dimensions. What we call coordinates were actually row and column indices of a 2001x2001 Matlab matrix which served as a discrete representation of this model. The fixed size of that matrix was required only by the computational limitations; it was not intended to simulate the directional theory's "region of acceptability". The radius of the circular model was arbitrarily set at the scalar value of 1.0, making the model extend from -1.0 to +1.0 along both dimensions. The circular shape of the model was chosen to avoid degeneracy of 
configurations resulting from multiple symmetry axes of other uniform geometric shapes.

Parties were labelled with FWHM values ranging from 0.2 , which represented a fringe party with the narrowest distinguishable voter base, to 1.0, which represented a catch-all party with the widest voter base. The FWHM values were based on the same arbitrary scalar unit used to size the model.

Voters were assumed to be voting deterministically, each voter favoring the party whose utility function was the highest at the voter's location. For example, in a competition between a minor party of $\mathrm{FWHM}_{2}$ $=0.5$ located at $\left(x_{2}=-0.25, y_{2}=+0.25\right)$ and a major party of $\mathrm{FWHM}_{1}=1.0$ located at $\left(x_{1}=+0.25, y_{1}=\right.$ 0.25 ) over the uniformly circular opinion space, assuming a contribution factor of $r_{d}=0.5$ for the directional component, the votes would be cast according to the highest voter utility values graphed in the figure below:

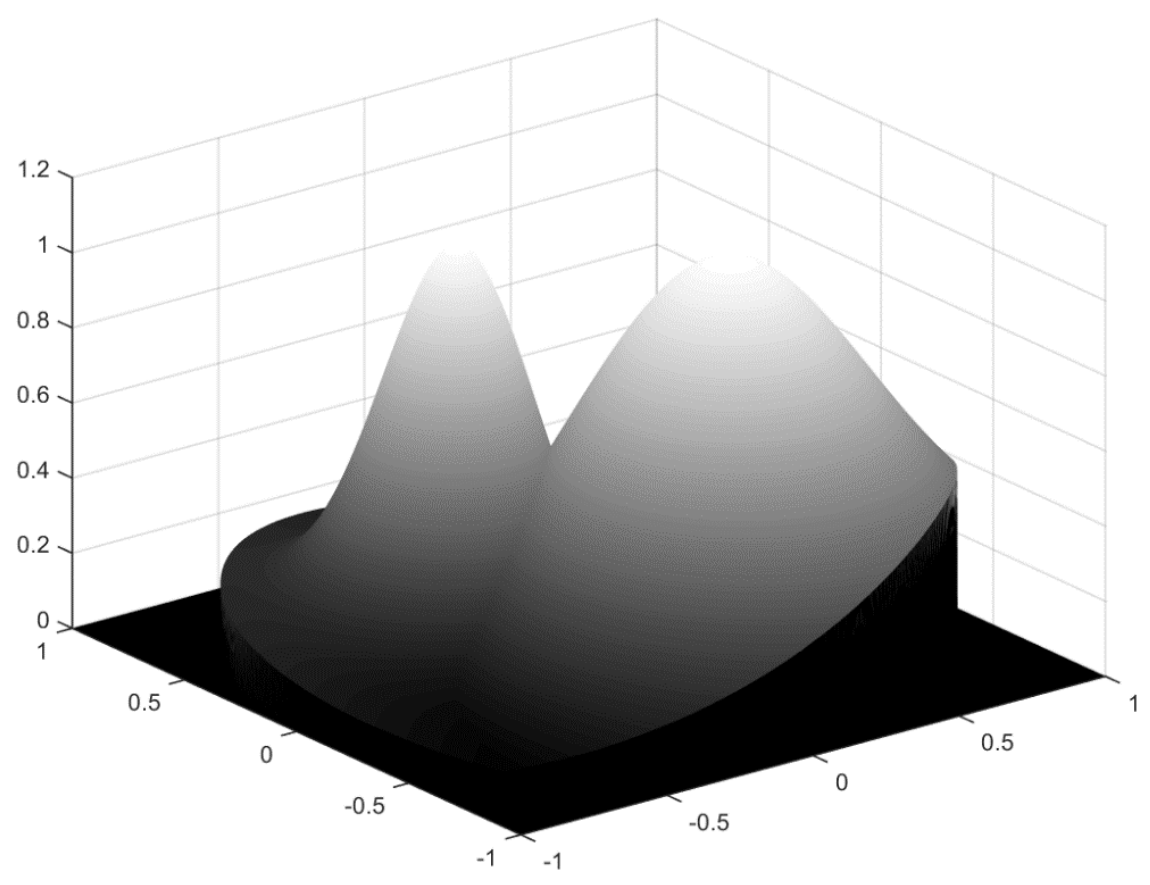

Figure 3. Three-dimesional model of the combined voter utility function for the competition between a major party with $\mathrm{FWHM}_{1}=1.0$ located at $\left(x_{1}=0.25, y_{1}=-0.25\right)$ and a minor party of $F W H M_{2}=0.5$ located at $\left(x_{2}=-0.25, y_{2}=+0.25\right)$ with a directional voting contribution ratio $r_{d}=0.5$

For every possible permutation of two or three FWHMs, party locations were initially set randomly within a sub circle of radius 0.8 over the model space and final optimum locations were found through an internal bounded optimization function of Matlab.

Optimizations were repeated fifty times for each FWHM combination to ensure that final equilibrium locations were unique. For the purpose of normalizing the locations, the major party with the greatest FWHM value in each trial was limited to move only along the $x$-axis at each optimization run.

\section{Results}

Optimum party locations (averaged over fifty trials for each FWHM combination) were found in Cartesian coordinates. These results will be furnished upon request. Since a party's voter base size mainly affects its distance from the neutral center of the idealized opinion space, here we present the graphs of radial locations as more meaningful visualizations.

The following figure shows the optimum location radii for a major party with $\mathrm{FWHM}_{1}=1.0$ for different $\mathrm{FWHM}_{2}$ values for the opposing party and directional component contributions varying from $r_{d}=0.0$ to $r_{d}=1.0$ : 


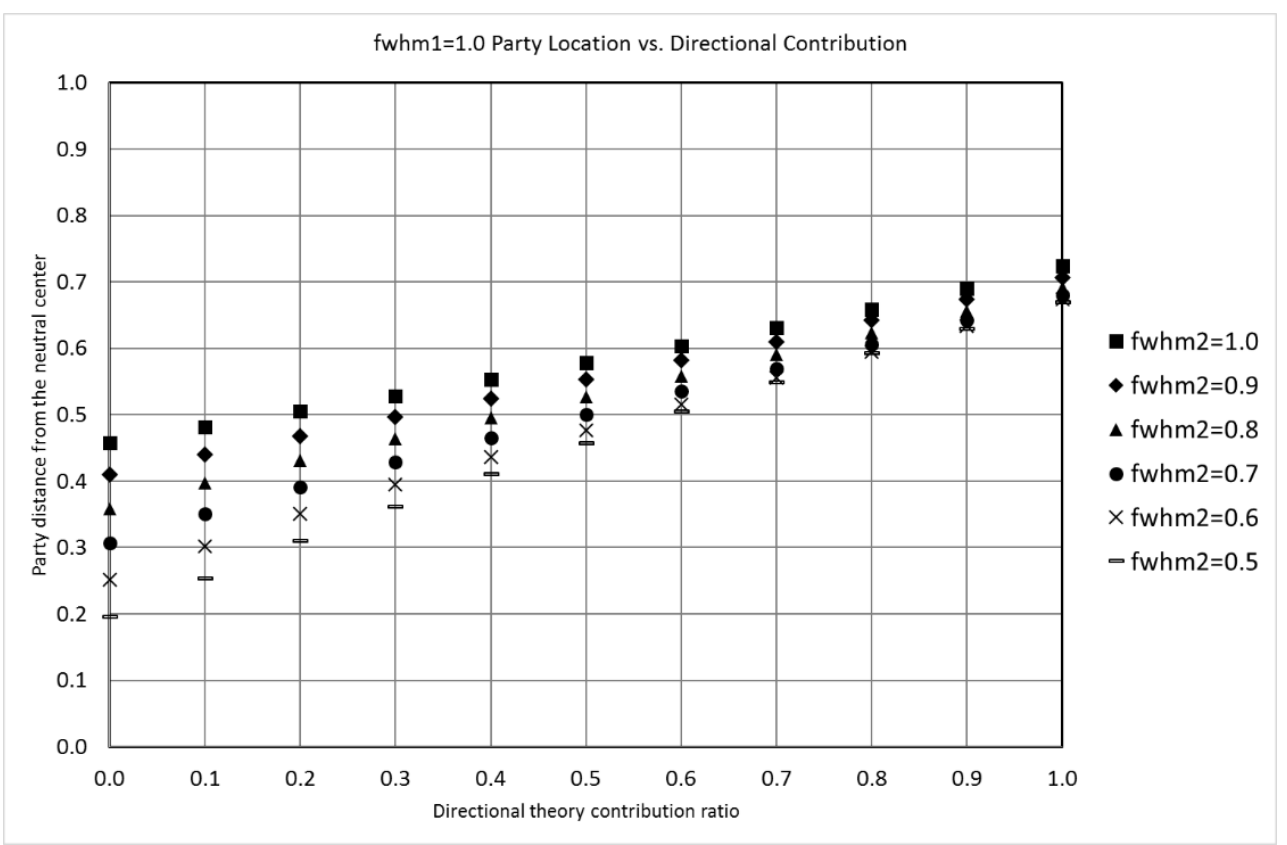

Figure 4. A plot of the radial location of a major party with $F W H M_{1}=1.0$ with respect to different $\mathrm{FWHM}_{2}$ values for the opposing party and directional voting contribution ratio

These results indicate that two rival parties competing in a way to maximize voter utility function always settle at optimum locations diametrically opposite to each other. While choosing opposite locations, the major party with the greater voter base collects the votes nearer the neutral center, forcing the minor party to seek votes away from the center. However, as the directional voting tendency gets stronger, the major party can appeal to less neural voters, while pushing the minor party further away, to even more radical circles near the boundary.

These results indicate that two rival parties competing in a way to maximize voter utility function always settle at optimum locations diametrically opposite to each other. While choosing opposite locations, the major party with the greater voter base collects the votes nearer the neutral center, forcing the minor party to seek votes away from the center. However, as the directional voting tendency gets stronger, the major party can appeal to less neural voters, while pushing the minor party further away, to even more radical circles near the boundary.

When we plot the location radii for a minor party of $\mathrm{FWHM}_{2}=0.5$ for the different values of the opposing party $\mathrm{FWHM}_{1}$ values and different directional component contribution ratios, we can see that increasing tendency of directional voting forces the minor party outside the bounds of the mathematical model: 


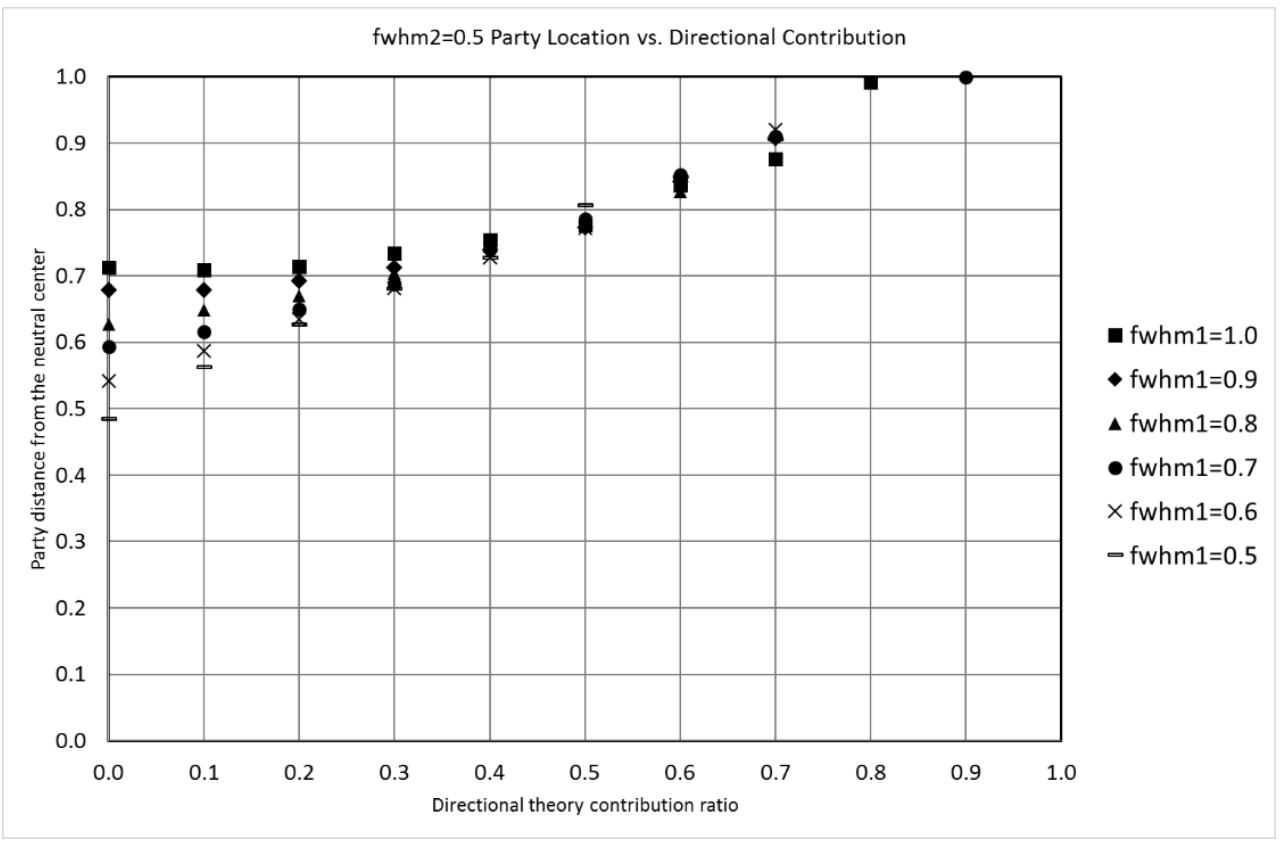

Figure 5. A plot of the radial location for a minor party with $\mathrm{FWHM}_{2}=0.5$ with respect to different FWHM values for the opposing party and directional voting contribution ratio

In three-party competitions, directional voting tendency has the same effect of allowing major parties to shift away from the center and pushing smaller parties to the edges of extremism.

The following figure shows the graph of three major parties with equal FWHMs of 1.0. While remaining equidistant from the center (hence the overlapping graph markers), forming an almost perfect equilateral triangle in every trial, three parties slowly shift away from the center as directional voting tendency gets stronger.

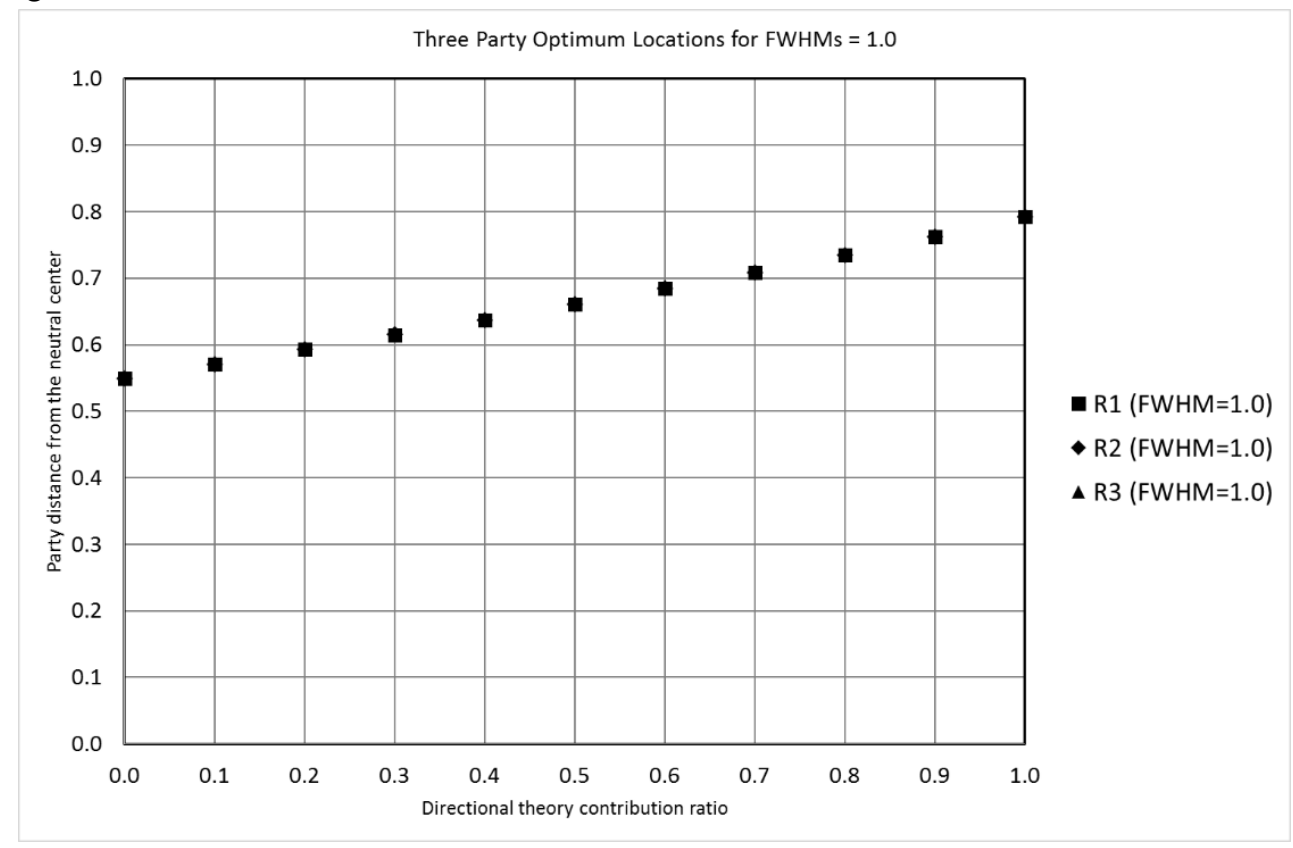

Figure 6. A plot of the -coinciding-radial locations of for three major parties with FWHMs $=1.0$ with respect to directional voting contribution ratio 
The following graph, on the other hand, compares the radial locations of three parties with different FWHMs and clearly shows how the minor parties are pushed outwards by the directional voting tendency.

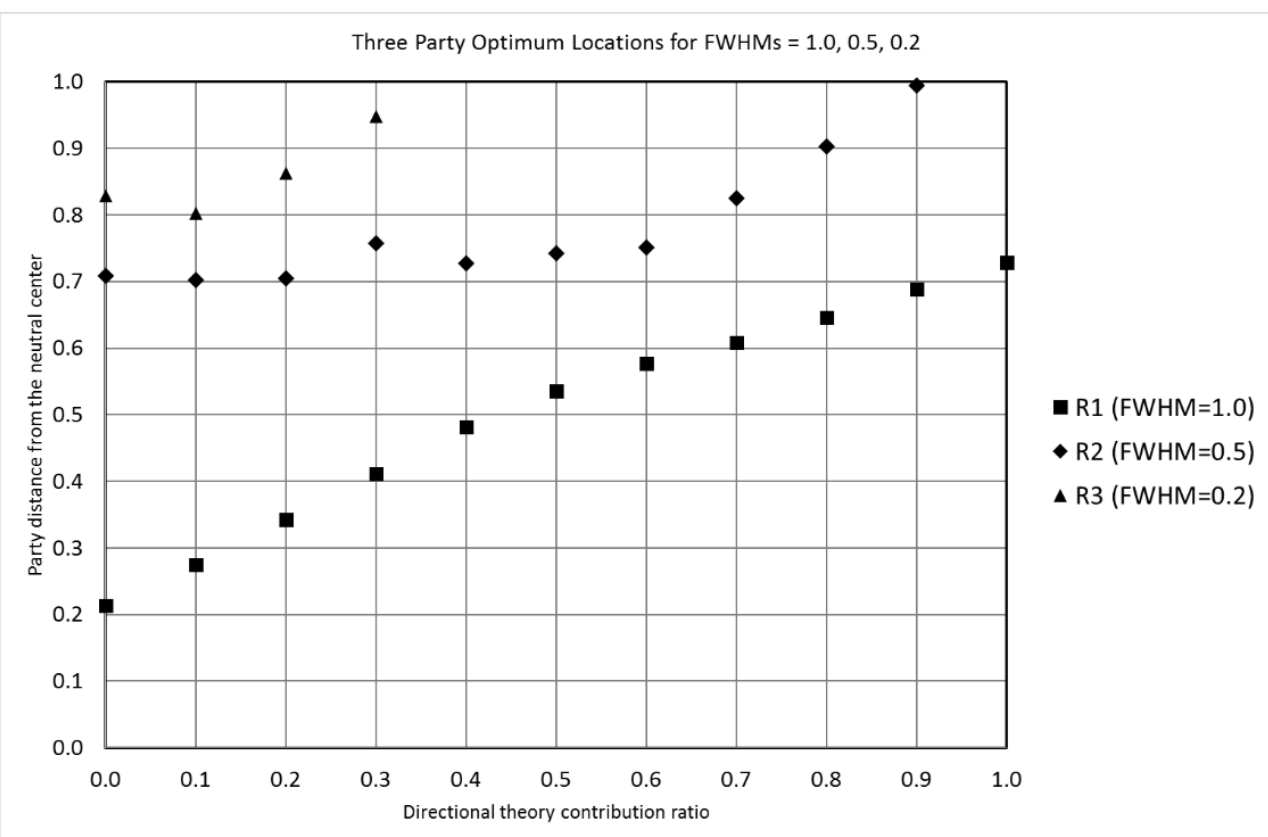

Figure 7. A plot of the radial locations of for three parties with $F W H M_{1}=1.0, F W H M_{2}=0.5$ and $\mathrm{FWHM}_{3}=0.2$ with respect to directional voting contribution ratio

\section{Summary and Discussions}

It is possible that neither theory's utility function sufficiently explains the overall voting behavior of all the voters. We argue that the inconclusiveness of the academic debate is partly due to the similarity of the voter utility functions attributed to those theories. This similarity may well be due to the inadvertent inclusion of the directional voting tendency in the proximity theory, which came earlier and thus provided a mixed representation of the voting behaviors of all voters with different levels of cognitive abilities. Our claim is that, every voter will be able to determine the ideological distance and hence the utility value of a party that he/she feels close, and the smooth decreasing part around a Gaussian function's peak represents this tendency to vote by proximity by a party's close supporters. It is the horizontally unbounded edges of the function that may appear unrealistic, because they imply that voters will feel indifferent to ideologically distant parties. One cannot ignore the strong possibility that a voter will feel repulsed by parties defending totally opposite points of view. Beyond the maximum ideological distance he/she can perceive, a voter will simply decide according to at which side a party is.

It is possible that the directional theory simply isolated this less demanding voting tendency in the form of a decreasing part explaining the repulsion felt towards parties defending opposite opinions and an increasing part to indicate the preference for a party on the same side, even if that party is not ideologically very close. However, the directional voting utility function, in its original form, does not prohibit a party from taking the most extreme positions without losing the support of even the mildest voters on the same side. If this study's virtual voters voted only directionally, all parties would shift out of the computational bounds and there would be no specific optimum locations for them to settle. The acceptability criterion was introduced to eliminate this implied support for the extremists (Rabinowitz \& Macdonald , 1989), but this addition implied that a voter sometimes judged a party or candidate by its distance, though he/she would not pay attention to the ideological distance for reasonable ones.

Having considered these points, we conclude that a mathematical function without a continuously decreasing part should be more appropriate for the proximity theory, which is mainly about explaining the variation in the affinity felt by a voter for a party. A Gaussian function seems perfect to explain the normal variation of voter utility value within small ideological distances, with the added benefit of the FWHM parameter as a measure of the party's voter base size. Considering that the directional voting tendency may become dominant for every voter beyond intermediate distances, it is preferable to utilize a linear combination of a non-repulsive proximity theory function and the directional theory function in its original, simple form. The multiplication factor for the directional theory function could be adjusted to determine the relative strength of the directional voting tendency. 
In the experiments conducted over the idealized model, the virtual voters perfectly knew the locations of parties and of themselves and voted deterministically for whichever party had the most utility value according to the combined function. This was clearly not a realistic simulation of the actual elections, but the model and the experiments were only intended to produce results which would provide clues about the factors affecting the relative placements of political parties in simulations. The optimum party locations found through the experiments indicated that the directional voting tendency would increase the radicalization levels of even the major parties with the greatest voter bases. The results support the relationship suggested between centrifugal placements of political parties and directional voting (Dinas, Hartman, \& van Spanje, 2016), but the direction of causality may be opposite to that suggested by other researchers (Lachat, 2008). We hence conclude that, the radicalizations levels of major parties indicate the likelihood that an average voter will vote directionally.

In summary, this study merely presents a computational viewpoint as a different way of comparing the two spatial voting theories. Admittedly, it sounds overly bold for proposing modifications the voter utility functions without much theoretical support from the existing literature. Laying the proper theoretical foundations will require more interdisciplinary studies conducted under the leadership of political scientists. The important thing is that, experiments and simulations must also be added to the tool set for comparing the theories. We have already mentioned an experimental study here (Lacy \& Paolino, 2010), but that one involved actual people substituting for voters deciding on fictitious candidates, and real people do not think in purely mathematical terms. Judging the merits of a voter utility function requires a mathematical model in which virtual voters decide solely according to the values returned by that function. The decisions of virtual voters, when compared with the decisions of actual voters, will guide the researchers on how to improve the voter utility functions and the voting theories associated with them. Mathematical models cannot provide accurate predictions about the outcomes of elections, but they will certainly be helpful in demonstrating the influences of the various parameters in a voter utility function and help construct a universally acceptable voting theory.

\section{References}

Boatright, R. G. (2008). Who are the spatial voting violators? Electoral Studies, 27, 116-125.

Chisik, R. A., \& Emke, R. J. (2006). When Winning is the Only Thing: Pure Strategy Nash Equilibria in a Three-Candidate Spatial Voting Model. Soc. Choice Welfare, 26, 209-215.

Davis, O. A., Hinich, M. J., \& Ordeshook, P. C. (1970). An Expository Development of a Mathematical Model of the Electoral Process. The American Political Science Review, 64(2), 426448.

Dinas, E., Hartman, E., \& van Spanje, J. (2016). Dead Man Walking: The Affective Roots of Issue Proximity Between Voters and Parties. Political Behavior, 38, 659-687.

Dow, J. K. (2001). A comparative spatial analysis of majoritarian and proportional elections. Electoral Studies, 20, 109-125.

Fazekas, Z., \& Meder, Z. Z. (2013). Proximity and directional theory compared: Taking discriminant positions seriously in multi-party systems. Electoral Studies, 32, 693-707.

Joesten, D. A., \& Stone, W. J. (2014). Reassessing Proximity Voting: Expertise, Party, and Choice in Congressional Elections. The Journal of Politics, 76(3), 740-753.

Johnson, P. E. (1989). Formal Theories of Politics: The Scope Of Mathematical Modelling in Political Science. Mathematical and Computer. Modeling, 12(4-5), 397-404.

Kedar, O. (2005). When Moderate Voters Prefer Extreme Parties: Policy Balancing in Parliamentary Elections. American Political Science Review, 99(2), 185-199.

Lachat, R. (2008). The impact of party polarization on ideological voting. Electoral Studies, 27, 687698. 
Lacy, D., \& Paolino, P. (2010). Testing proximity versus directional voting using experiments. Electoral Studies, 29, 460-471.

Leimgruber, P., Hangartner, D., \& Leeman, L. (2010). Comparing Candidates and Citizens in Ideological Space. Swiss Political Science Review, 16(3), 499-531.

Lewis, J. B., \& King, G. (1999). No Evidence on Directional vs. Proximity Voting. Political Analysis, $8(1), 21-33$.

McDonald, S. E., Listhaug, O., \& Rabinowitz, G. (1991). Issues and Party Support in Multiparty Systems. The American Political Science Review, 85(4), 1107-1131.

McDonald, S. E., Rabinowitz, G., \& Listhaug, O. (1995). Political Sophistication and Models of Issue Voting. British Journal of Political Science, 25(4), 453-483.

McDonald, S. E., Rabinowitz, G., \& Listhaug, O. (1998). On Attempting to Rehabilitate the Proximity Model: Sometimes the Patient Just Can't Be Helped. The Journal of Politics, 60(3), 653-690.

Pardos-Prado, S., \& Dinas, E. (2010). Systemic polarisation and spatial voting. European Journal of Political Research, 49, 759-786.

Rabinowitz, G., \& Macdonald, S. E. (1989). A Directional Theory of Issue Voting . The American Political Science Review, 83(1), 93-121.

Schofield, P. (2007). Political equilibria with electoral uncertainty. Social Choice and Welfare, 28, 461-490.

Serra, J. (2018). Probabilistic Ideal Points: A General Spatial Model of Voting.

Shane, P. S., \& Roy, J. (2014). Political knowledge, the decision calculus, and proximity voting. Electoral Studies, 34, 89-99.

Tomz, M., Houweling, R. P., \& Sniderman, P. M. (2006). New Evidence on Directional versus Proximity Voting. Midwest Political Science Association. Chicago.

Westholm, A. (1997). Distance versus Direction: The Illusory Defeat of the Proximity Theory of Electoral Choice. American Political Science Review, 91(4), 865-883. 